\title{
PRECEPTORIA NA RESIDÊNCIA MÉDICA EM HOSPITAL PÚBLICO DE EMERGÊNCIA ALÉM DAS ATIVIDADES PRESCRITAS: RELATO POR MEIO DE INCIDENTES CRÍTICOS
}

\section{MEDICAL RESIDENCY PRECEPTORSHIP AT A PUBLIC EMERGENCY HOSPITAL BEYOND PRESCRIBED ACTIVITIES: REPORT OF CRITICAL INCIDENTS}

\author{
Camille Lemos Cavalcanti Wanderley ${ }^{1}$ \\ Maria de Lourdes Fonseca Vieira ${ }^{2}$ \\ Maria Viviane Lisboa de Vasconcelos ${ }^{3}$
}

\begin{abstract}
Resumo: As Diretrizes Curriculares Nacionais da Medicina enfatizam a lacuna existente no ensino de emergência e a especificidade da preceptoria nesse cenário. Este estudo analisa a influência dos fatores psicossociais do trabalho no fazer pedagógico do preceptor, numa abordagem qualitativa, na modalidade estudo de caso. Foi desenvolvido em hospital público de emergência do nordeste do Brasil. Participaram cinco preceptores de Residência Médica, submetidos à entrevista individual através da técnica do incidente crítico. Os dados foram submetidos à análise de conteúdo, a partir da qual foram identificados os fatores psicossociais inerentes ao trabalhador e internos ao trabalho que influenciam a preceptoria. As evidências destacam ainda a reduzida formação pedagógica e a imobilização do poder de agir em competência dos preceptores, sendo necessário o fortalecimento da formação pedagógica e da identidade profissional. Ressalta-se a necessidade de problematizar o cotidiano do processo de trabalho em saúde para transformar a formação de quem forma.
\end{abstract}

Palavras-chave: Preceptoria; Residência médica; Análise e Desempenho de Tarefa; Hospital de emergência; Clínica da Atividade.

Abstract: The National Curricular Guidelines of Medicine emphasize the gap in emergency teaching and the specificity of the role of preceptor in this setting. The present study analyzes the influence of the psychosocial factors of work on the pedagogic performance of preceptors, using a qualitative approach and a case study. The research was conducted at a public emergency hospital in Northeastern Brazil. The five preceptors from the medical residency that participated were interviewed individually using the critical incident technique. The data were submitted to content analysis and the psychosocial factors inherent to the worker and specifically to the work that influences preceptors were identified. The evidence highlights insufficient pedagogic training and the lack of action on behalf of preceptors, demonstrating the need for strengthening pedagogical training and professional identity. It is important to investigate the daily work process in health, in order to transform training procedures.

Keywords: Preceptorship; Medical residency; Task and performance analysis; Emergency hospital; Activity clinic.

\footnotetext{
${ }^{1}$ Mestre em Educação na Saúde pela Universidade Federal de Alagoas (UFAL). Professora assistente do Centro Universitário Tirandentes (UNIT), Maceió, Alagoas, Brasil. E-mail: camillewanderley@hotmail.com

${ }^{2}$ Doutora em Saúde da Criança e do Adolescente pela Universidade Estadual de Campinas (UNICAMP). Professora associada da Faculdade de Medicina da Universidade Federal de Alagoas (UFAL), Maceió, Alagoas, Brasil. E-mail: vieiramlf@gmail.com

${ }^{3}$ Doutora em Saúde da Criança e do Adolescente pela Universidade de São Pulo (USP). Professora associada da Faculdade de Medicina da Universidade Federal de Alagoas (UFAL), Maceió, Alagoas, Brasil. E-mail: camposlisboa@gmail.com
} 


\section{Introdução}

A formação dos profissionais de saúde tem sido delineada, ao longo dos anos, por uma organização de atenção à saúde baseada na ciência positivista. Sob essa forma, conhecimento e o saber são fragmentados e reduzidos à busca pela eficiência técnica e pelo cuidado integralizado (SILVA; MATOS; FRANÇA, 2017).

Nesse sentido, a Organização Mundial de Saúde aponta a importância da educação e da formação dos profissionais de saúde (WORLD HEALTH ORGANIZATION, 2013). O redesenho é necessário e oportuno, tendo em vista a aceleração dos fluxos de conhecimento, tecnologia e financiamento; a oportunidade de mútua aprendizagem; as soluções conjuntas oferecidas pela interdependência das fronteiras e a migração de profissionais e pacientes (FRENK et al., 2010).

No Brasil as Diretrizes Curriculares Nacionais (DCN) transformam-se no condutor de um movimento de mudanças na formação dos profissionais de saúde. É com base nelas que são construídos os cuidadosos arranjos de inovação em direção à uma formação geral, humanista e orientada para a integralidade (FEUERWERKER, 2014).

Porém, toda essa análise de cenário precisa impactar a formação médica, que desde sua origem depende fortemente do componente prático. O treinamento em serviço nasceu com o ensino médico, no qual o processo de capacitação deveria articular ensino e aprendizagem de forma coesa. A Residência Médica (RM) foi instituída no Brasil pelo Decreto $\mathrm{n}^{\circ} 80.281$, de 05 de setembro de 1977, sendo considerada a mais eficaz forma de inserção de médicos sob supervisão na vida profissional, bem como um modelo de capacitação para especialistas (BRASIL, 1977; SOARES et al., 2013). Da criação da Comissão Nacional de Residência Médica (CNRM) até os dias atuais, inúmeros programas de residência médica foram implementados sem o devido preparo dos preceptores para a formação dos aprendizes.

A Residência Médica desempenha papel estratégico, uma vez que sua natureza metodológica está centrada no ensino pelo trabalho, utilizando-se do dispositivo da educação permanente e buscando a formação de médicos especialistas para a demanda da população (BRASIL, 2006).

Diante desta realidade, o preceptor - profissional que acompanha o aluno no cenário prático, ensinando enquanto exerce suas atividades cotidianas - possui, de acordo com Botti e Rego (2011), vários papéis no processo de formação da Residência Médica, 
aproximando-se das figuras do orientador, do supervisor, do tutor, do mentor e do docente-clínico.

Cabe ao preceptor a tarefa de preparar um novo modelo de profissional médico. Entretanto, faz-se necessário superar as lacunas ainda existentes na formação majoritariamente deficitária dos preceptores, uma vez que tais profissionais possuem apenas especialização na área da saúde e quase nunca na da educação (AFONSO; SILVEIRA, 2012).

Assim sendo, é exigido que o preceptor renove, reconstrua e refaça a profissão (CASTELLS; CAMPOS; ROMANO, 2016). Diante de tantos desafios apresentados, é necessário relacionar as competências essenciais para a identidade profissional do preceptor, que, em sua atividade, precisa estabelecer uma nova relação com as instituições, com o programa e com os residentes (AFONSO; SILVEIRA, 2012).

O cenário das práticas do preceptor da RM de um hospital público de emergência é atravessado por grande demanda, vulnerabilidade e superlotação, fatores que acabam prejudicando o atendimento e sobrecarregando a equipe de profissionais (GOLDIM, 2003; GARLET et al., 2009).

O excesso de atribuições dos médicos acarreta dificuldades no processo de ensinoaprendizagem dos estudantes, que precisam de preceptores para aprender os cuidados com o paciente (VALENTIM; SANTOS, 2009). Os profissionais não se sentem estimulados e capacitados para o exercício da preceptoria, o que dificulta a inserção dos estudantes na rede (SANT'ANA; PEREIRA, 2016). A capacitação do preceptor com o atendimento de emergências continua sendo um grande desafio, postas a grande demanda e a sobrecarga dos serviços (BRASIL, 2002).

Ressaltamos que a emergência é atravessada por fatores psicossociais do trabalho e que estes, segundo a Organização Internacional do Trabalho (OIT), são definidos como a interação entre o ambiente de trabalho, o conteúdo do trabalho, as condições organizacionais e as capacidades, necessidades, cultura e considerações pessoais extra emprego que podem, através da percepção e da experiência, influenciar a saúde, o desempenho e a satisfação no trabalho (INTERNATIONAL LABOUR ORGANIZATION, 1986). Sendo assim, a natureza dos fatores psicossociais é complexa e os processo e organização do trabalho são, nas unidades de urgência ou emergência do sistema público brasileiro, acentuadamente marcados por essas relações psicossociais paradoxais (DAL PAI; LAUTERT, 2008). 
De tal modo, o fenômeno trabalho é um objeto de estudo compartilhado por várias ciências, uma delas sendo a Psicologia Organizacional e do Trabalho. Para entender o fenômeno, a base teórica desse campo da Psicologia é delineada pelas clínicas do trabalho. Apesar da confusão, o termo clínica, para tal campo, não se refere ao atendimento individual; ele considera o trabalho como categoria central na relação subjetividade-saúde-sofrimento. Segundo Lima (2011), as clínicas do trabalho buscam compreender a relação entre fatores subjetivos e atividade. As principais abordagens em clínica do trabalho são: psicodinâmica do trabalho, psicossociologia, ergologia e clínica da atividade. Esta pesquisa está ancorada na perspectiva teórica da Clínica da Atividade, que surge na década de 1980 situada no desenvolvimento da ergonomia francesa. Sendo assim, a Clínica da Atividade advém de uma transformação do trabalho que é fruto da análise do próprio trabalhador, convidando este a ser protagonista dos processos de mudança, com uma contribuição, sobretudo, metodológica. A perspectiva tem como referência Yves Clot e Daniel Faita (NAUJORKS, 2018).

As noções de atividade, poder de agir e gênero profissional destacam-se na perspectiva da Clínica da Atividade. A atividade é o que relaciona o indivíduo e o social, o sujeito e a organização do trabalho e os sujeitos entre si, bem como esses sujeitos e os objetos que os mobilizam (CLOT, 2010).

Nas organizações a análise da atividade evidencia a relação entre o trabalho prescrito, o trabalho realizado, os sentidos dados e produzidos a partir do trabalho e as intervenções dos trabalhadores, individual ou coletivamente (TELLES; ALVAREZ, 2005).

A partir do trabalho prescrito e do real, Clot et al., (2006) propõem acrescentar a noção de real da atividade, inserindo, além daquilo que deve ser feito e do que efetivamente se faz, aquilo que não pode ser observado diretamente. Com isso a relação que o sujeito estabelece com o prescrito, bem como com o conjunto das mediações intersubjetivas que lhe dão sustentação, torna-se passível de observação no desenrolar da atividade (NAUJORKS, 2018).

O poder de agir, por sua vez, permite avaliar o alcance da ação efetiva do sujeito na sua esfera de trabalho corriqueira (CLOT, 2010). O poder de agir está ligado ao cuidado e à realização de um trabalho percebido como bem executado e, daí, a um reconhecimento, que pode ser individual ou coletivo, de uma história profissional (CLOT, 2010). 
Clot (2008) e Clot et al., (2006) classificam o gênero da atividade profissional a partir do conceito de gênero de discurso de Bakhtin (2003). O gênero profissional seria um referencial comum de conhecimentos eficazes que se constrói a partir de regras não escritas e mutáveis, ou seja, mecanismos de cooperação entre trabalhadores nos quais se encontram regras formais e informais de ação comum.

Nesse quadro, remetemos à noção de trabalho como tendência criadora que privilegia a dimensão potencializadora da vida em seus múltiplos aspectos - sendo fonte de alteridade, de iniciativa e de criatividade -, desde que permita a expansão do poder de agir do trabalhador (CLOT, 2011). Os esforços nas legislações em prol das transformações na formação médica vigentes no país não estão sendo suficientes e seu impacto não consegue dar respostas mais efetivas às demandas de saúde da sociedade. Um dos grandes desafios para a qualificação das residências em saúde é a ausência de referencial pedagógico em educação permanente no processo de ensino (SHIKASHO, 2013). Sendo assim, pretende-se discutir a resposta à pergunta da pesquisa: Quais fatores psicossociais do trabalho influenciam o exercício pedagógico do preceptor da Residência Médica em um hospital público de emergência? O propósito desta pesquisa é analisar a influência dos fatores psicossociais do trabalho no fazer pedagógico do preceptor da Residência Médica em um hospital público de emergência. Para tanto, debateremos a subjetividade presente no trabalho docente dos preceptores da Residência Médica sob o ponto de vista da Clínica da Atividade.

\section{Percurso metodológico}

\subsection{Desenho da pesquisa}

Este trabalho é uma investigação exploratória do tipo estudo de caso único e emprega uma abordagem qualitativa. O estudo de caso é uma estratégia metodológica caracterizada pela investigação dos fenômenos contemporâneos em profundidade, dentro de seu contexto real de vida. Tem seu suporte em plataforma teórica e busca apreender a totalidade de uma situação normalmente complexa e que envolve diversas dimensões (MARTINS, 2008). A abordagem qualitativa favorece este trabalho, uma vez que, ao lidar com percepções, entra no espaço da subjetividade, que não pode ser medida quantitativamente, e fornece condições de readaptação e correções de instrumentos de pesquisa no decorrer da mesma (MINAYO, 2004). 


\subsection{Cenário da pesquisa}

O estudo foi desenvolvido em um hospital público de emergência na cidade de Maceió/Alagoas, nordeste do Brasil, que atende a todas as necessidades do Sistema Único de Saúde (SUS) do estado. A instituição se caracteriza pelo funcionamento acima de sua capacidade máxima, pela escassez de profissionais, pela demanda inadequada e por verba financeira insuficiente. O hospital é tido como referência no processo de formação na área da saúde. A Residência Médica do hospital teve seu primeiro edital em 2016 e, atualmente, oferta vagas para clínica médica, neuroclínica, pediatria, medicina de emergência, ortopedia e traumatologia.

\subsection{Procedimentos}

Esta pesquisa utilizou adaptação da Técnica do Incidente Crítico (TIC), estabelecida por Flanagan (1954), para a coleta de dados. O método consiste numa forma de obtenção de dados qualitativos, utilizada nas últimas décadas na área de saúde pela sua capacidade de acessar a subjetividade das pessoas que vivenciaram determinadas situações (RIBEIRO, 2012).

Por incidente crítico (IC) entende-se qualquer fato inesperado e traumático, em qualquer atividade humana, que gere uma resposta emocional intensa e condicione a habilidade no seu desempenho no trabalho e/ou nas suas atividades pessoais (BARROS et al., 2017).

A coleta de dados ocorreu por meio da aplicação de formulário com perguntas de respostas binárias ( $\operatorname{sim} /$ não) para caracterização dos sujeitos, bem como da utilização de entrevista semiestruturada. Esse último instrumento teve como disparadores três incidentes críticos previamente elaborados e que versam sobre situações do cotidiano do preceptor da RM.

A construção dos incidentes críticos se deu mediante observação e vivência da pesquisadora no cotidiano do hospital pesquisado, envolvendo a dimensão relacionada aos fatores psicossociais inerentes ao trabalhador, além dos internos e externos ao trabalho.

Os três incidentes críticos estavam em consonância com o objetivo da pesquisa e foram selecionados por conter situações próprias da atividade do preceptor da RM, bem como aspectos presentes na emergência pública. Destacam-se: improvisação dos protocolos da assistência, recursos limitados para fechar diagnósticos, tempo limitado 
para a assistência/docência, demanda acima da capacidade instalada, força de trabalho deficitária, interferência política, imprevisibilidade e falta de insumos para os procedimentos. Em todos eles estiveram presentes os aspectos cognitivos, afetivos e de resolutividade da situação.

Dando continuidade à coleta de dados, destacamos que a pesquisadora foi a própria entrevistadora. No momento da entrevista explicou-se a noção de incidente crítico e do objetivo da mesma, bem como foi realizada a leitura dos incidentes. Em seguida, foi solicitado que os preceptores evocassem memórias de fatos semelhantes, positivos e/ou negativos, do cotidiano do ensino da Residência Médica. Assim, foi possível explorar amplamente as seguintes questões: O que aconteceu? Com quem? Onde? Quando? O quê fez com que acontecesse? Quem agiu? Quais efeitos provocou? Que significado tem o que aconteceu?

Sendo assim, o objetivo da TIC foi levantar relatos de ICs da atividade pedagógica do preceptor da RM de um hospital público de emergência; relatos que apresentassem a influência dos fatores psicossociais do trabalho no comportamento do preceptor e nas consequências do seu fazer pedagógico.

As entrevistas eram suspensas no momento em que ocorria a saturação, instante no qual o entrevistador identificava que os ICs não contribuíam mais para a reflexão teórica, como também conseguia levantar a presença de incidentes heterogêneos o suficiente para responder à pergunta da pesquisa: quais fatores psicossociais do trabalho influenciam o exercício pedagógico do preceptor da Residência Médica em um hospital público de emergência? Todas as entrevistas foram gravadas, tendo duração média de 22 minutos, e posteriormente transcritas na íntegra pela própria pesquisadora, totalizando 53 páginas de material transcrito. Não houve perda de respostas e outras implicações para a pesquisa. Os dados foram armazenados e codificados através de senha no computador pessoal da pesquisadora.

\subsection{Análise dos dados}

O estudo dos dados foi realizado por meio da análise de conteúdo temática (MALHEIROS, 2011; BARDIN, 2011). Para preservar a identidade e o anonimato, os preceptores foram identificados, em suas falas, por cores, seguidas do número correspondente à ordem cronológica das entrevistas. Os colegas de trabalho desses preceptores foram identificados pelos pseudônimos José e Antônio. 
Nas entrevistas realizadas foram identificados oito incidentes críticos, selecionados a partir das falas dos preceptores. Para a caracterização do IC, foram levadas em consideração as situações que, vivenciadas no cotidiano da preceptoria, originaram comportamentos e consequências no exercício pedagógico do preceptor. Dessa forma, os relatos tomados nesta pesquisa são textos grandes, uma vez que oriundos dos cenários dos incidentes críticos.

Para a realização da análise de conteúdo, foi estabelecida a dimensão dos fatores psicossociais do trabalho, tendo como referencial teórico Zanelli e Kannan (2018), que evidenciam as proporções relativas aos ambientes interno e externo ao trabalho, bem como as questões inerentes ao próprio preceptor. O estudo foi submetido ao Comitê de Ética em Pesquisa (CEP) da Universidade Federal de Alagoas (UFAL) - Plataforma Brasil e aprovado com o parecer de número 83797617.3.0000.5013. Todos os participantes assinaram o Termo de Consentimento Livre e Esclarecido (TCLE).

\subsection{Resultados e discussões}

O delineamento das características dos preceptores que participaram da pesquisa evidencia a predominância do sexo feminino, com idade entre 36 e 45 anos, além de vínculo efetivo de 20 a 30 horas semanais com a instituição. No tocante à formação acadêmica, possuem especialização, sem formação pedagógica e permanente em saúde no hospital. São responsáveis por mais de três residentes e não recebem remuneração para desempenhar a função. Todos foram levados a exercer a preceptoria por uma identificação pessoal. Esse delineamento teve como base o recorte das informações pessoais, formação e vínculo profissional, que estruturaram os itens do formulário sociodemográfico de caracterização dos sujeitos.

É relevante mencionar que a separação dos fatores psicossociais do trabalho contribui para aprofundar a discussão dos achados, porém eles não são excludentes. Tais fatores se inter-relacionam sempre que trabalhador e condições de trabalho se entrelaçam para criar as condições para agir (ou não) no processo de ensino-aprendizagem, o que reflete no repertório de competências pedagógicas utilizadas pelo preceptor. Destaca-se que emergiram duas categorias temáticas: fatores psicossociais inerentes ao trabalhador e fatores psicossociais internos do trabalho. Em seguida, apresentamos e discutimos as categorias sob o olhar da clínica da atividade, procurando entender a dinâmica subjetiva 
presente na atividade do preceptor da emergência, que imobiliza ou não o seu poder de agir.

\subsubsection{Categoria I: Fatores psicossociais inerentes ao trabalhador}

Os fatores inerentes ao trabalhador estão relacionados às características pessoais, próprias desses preceptores, destacando-se como uma das categorias presentes na pesquisa, englobando características demográficas, autoestima e autoconhecimento, lócus de controle, capacidade de enfrentamento/adaptação, habilidades sociais e espiritualidade (ZANELLI; KANNAN, 2018).

Para Clot et al., (2006), o trabalho possui uma função psicológica específica, sendo visto como atividade que transforma o mundo e a subjetividade dos trabalhadores. Na Clínica da Atividade, a utilização da linguagem é valorizada como algo de grande importância. Clot (2010, p. 26) afirma que "[...] a verbalização é uma atividade do sujeito em si mesma e não apenas um meio de acessar outra atividade”. Desse modo, cada sujeito tem a possibilidade de reformular sua ação ao se dirigir aos demais nesse movimento dialógico, encontrando, sem forçosamente procurar, algo novo de si mesmo.

Dessa forma, através dos diálogos que se seguem, os preceptores foram provocados a exercitar a reflexão diante do seu exercício profissional. Nessa categoria são apresentadas situações vivenciadas pelos participantes da pesquisa que tiveram seu fazer pedagógico perpassado por fatores psicossociais inerentes ao trabalhador, com destaque para o lócus de controle, sendo possível observar o impacto desse fator no exercício da preceptoria.

[...] Eu cheguei uma vez na enfermaria, tinham quatro estudantes, as quatro estavam chorando. Na verdade, tinha cinco, a quinta, ah, ah [ri], eu proibi de chorar. As outras quatro estavam chorando porque faltava [...] o tomógrafo estava quebrado, aí não tinha como fazer os exames. A bioquímica, metade faltava reagente, a outra [refere-se a outra aluna que chorava], uma transferência onde a ambulância tava mandando outros pacientes para dialisar no *** [hospital de contrarreferência] e não tinha condições de levar essa [refere-se a uma paciente] [...]. Enfim, estavam chorando. Aí, eu fui consolar: "Minha gente, aqui não é ruim". "Doutora, aqui é péssimo" [resposta das estudantes], ah, ah [ri], eu respondi: "Não, minha filha, não é assim, não. É porque hoje..." [...] "Hoje não, hoje é o seu dia, foi a semana toda acontecendo isso" [resposta da residente]. (Amarela 1).

[...] Eu vi um paciente, que era um paraplégico, cheio de escara com sonda, com sonda cheia de grumo, infecção. Eu olhei, que confusão! Aí, eu fui pegar o prontuário do paciente, o paciente tinha várias culturas positivas, mas que tinha chegado desde a semana anterior, mas não tinha sido entrado no antibiótico para ele, maluquice, confusão é isso aqui. Vinha chegando os alunos, aí eles chegaram, se apresentaram e eu perguntei: "Quem é que tá com o paciente tal?". Aí, o rapaz [residente] disse: "Sou eu, doutora". Eu disse: 


\begin{abstract}
"Meu filho, me explique uma coisa: como é que o paciente está assim, assim, assim, com cultura positiva, com sinal de infecção e ainda não foi tratado?". Ele [residente]: "Não, doutora, é que a gente passou na sexta-feira, que eu não estava [fala da preceptora], e foi decidido que, como ele tem sequelas neurológicas e ele vai fazer infecção sempre, não precisa nem tratar". "Como é, meu filho?" [questionamento da preceptora]. Aí, ele [residente] foi e repetiu, tranquilamente, sem o menor constrangimento. Foi uma coisa tão impactante que eu sentei. (Laranja 4).
\end{abstract}

As falas citadas retratam a expectativa que os preceptores estabelecem sobre o trabalho prescrito, que exige deles intensidade do seu próprio controle para a realização do trabalho real. A clínica da atividade de Clot (2007) remete esse olhar ao trabalho em cena, no qual os aspectos subjetivos e cognitivos sintonizados com o vir-a-ser do e pelo trabalho saem do universo da matéria e dos moldes preestabelecidos de trabalho. Sendo a atividade do trabalho o esforço intenso empreendido pelo trabalhador, no sentido de gerir a distância entre o prescrito e o real, foge-se da noção de que o trabalho corresponde, em qualquer caso, à mera execução (BORGES, 2004).

A relação cotidiana que o preceptor estabelece com seu contexto é necessariamente mediada pelos significados que o mesmo atribui à sua ação, à situação em que está envolvido, aos outros indivíduos e a si mesmo. Aqui, a identidade do preceptor é posta como um processo psicossocial de construção de significados e sentimentos de si e dos outros (NAUJORKS, 2018).

Por conseguinte, na Clínica da Atividade a subjetividade diz respeito ao poder de ser impactado, não estando o poder de agir separado desse poder de impactar. Sendo assim, o tempo todo o trabalhador encontra-se cheio de possibilidades não vivenciadas que possuem o poder de um campo de força no qual o sujeito pode agir (ROCHA; AMADOR, 2018).

Dessa forma, eclodem comportamentos que nem sempre evocam o pensamento crítico-reflexivo do preceptor em relação ao processo de ensino e aprendizagem - o que podemos verificar neste trecho da fala de Amarela 1: “[...] Eu proibi de chorar [...] Aí, eu fui consolar: 'Minha gente, aqui não é ruim"”. Quando Amarela 1 proibiu que as residentes chorassem, ela agiu de acordo com a formação e os valores que possui, utilizando o lócus de controle para passar pela situação. É possível observar, na fala de Laranja 4, que o controle foi evocado para dar conta do que fugiu do previsto: "Foi uma coisa tão impactante que eu sentei”. Nessas relações o cotidiano do trabalho possibilita o emergir da identidade profissional em situação: o trabalho e os pertencimentos organizacionais compõem a trajetória de uma infinidade de identidades postas e/ou possíveis (NAUJORKS, 2018). Assim os achados se fortalecem com o pensamento de 
Perrenoud et al., (2002), em sua obra sobre as competências para ensinar no século XXI, quando afirmam que a formação inicial desses profissionais está mais baseada em uma visão prescritiva da profissão do que em uma análise precisa de sua realidade.

Também nessa categoria, é possível destacar a capacidade de enfrentamento dos preceptores, que está relacionada aos esforços e estratégias para lidar com situações de estresse, ameaças e desafios, bem como às habilidades sociais que focam os comportamentos em um contexto interpessoal e sua adequação, em termos de respeito aos demais e de coerência consigo mesmo. Através dos relatos do preceptor Amarela 1, foi possível verificar o atravessamento das atividades docentes da preceptoria na emergência, tangenciado por esse fator psicossocial do trabalho, com impacto no seu poder de agir.

[...] Outra coisa que me impactou. O José [pseudônimo de outro médico preceptor], não sei se ele vai falar, ele teve um paciente que teve que fazer uma endoscopia de urgência e, aqui, o endoscópio estava quebrado. O José conseguiu uma endoscopia de cortesia no *** [hospital de contrarreferência] com o Antônio *** [pseudônimo do médico endoscopista], que é endoscopista daqui também. O Antônio só tinha até $4 \mathrm{~h}$ da tarde de sexta-feira. Não tinha transporte para levar o paciente, o José botou o paciente e a mãe dentro do carro [pessoal] e levou. Os residentes ficaram parados, assim, parados na porta. Como se quisessem dizer "eu não acredito que ele esteja fazendo isso" [fala com orgulho]. O José ligou para o Antônio. O Antônio: "José, só estou esperando, só estou esperando esse paciente. Eu vou embora". O José: "Não, Antônio, espere, eu vou". Aí, o José bota o paciente no carro com a mãe [do paciente]. Foi e trouxe de volta. E quem readmitiu ele [paciente] fui eu, às $7 \mathrm{~h}$ da noite, quando voltou, para o menino subir para a ala $\mathrm{E}$, porque o Antônio fez, era uma endoscopia com escleroterapia, porque o menino [paciente] não conseguia deglutir. Tudo ele vomitava, ele tava totalmente desnutrido. Ia chegar o fds [fim de semana] e não ia ter quem fizesse, porque o endoscópio estava quebrado e, se uma pessoa se prontificou a ajudar, a gente tem que ajudar também. Esse fato foi marcante, inclusive para os residentes na época. (Amarela 1).

A necessidade de gestão das variabilidades no decorrer do trabalho possibilita o debate do preceptor consigo mesmo, na medida em que o trabalho real sobrepõe-se ao prescrito e que, nesse caso, o trabalhador acaba por se ver convocado a entrar em atividade.

O preceptor utilizou o regime de regulação profissional, ou seja, aquele feito pelos trabalhadores de saúde, especialmente pelos médicos, via contatos pessoais, relações de conhecimento e confiança, que produzem fluxos de pacientes que podem respeitar, em parte, os caminhos e regras da regulação formal; ou seja, a regulação prescrita (CECILIO, 2012). Destaca-se que essa regulação não é ensinada através de portarias ministeriais ou protocolos de assistência à saúde das redes de atenção do Sistema Único de Saúde: essas 
práticas informais e em constante transformação se estabelecem através dos coletivos profissionais.

No relato do incidente crítico acima, o preceptor Amarela 1 evidencia o gênero profissional que o colega teve que utilizar, mobilizando recursos como o conhecimento e os favores de outros profissionais para garantir a assistência do paciente. Este - o gênero - garante a pertença do sujeito a um coletivo, sendo, igualmente, uma ferramenta para ação (CLOT et al., 2006). Ele permite que os pares se reconheçam, se comuniquem e atuem conjuntamente, mesmo quando nunca o fizeram previamente (CLOT, 2007).

$\mathrm{Na}$ atividade relatada por Amarela 1, estão presentes microescolhas relacionadas aos valores e ao significado que o exercício da preceptoria tem para o preceptor. Quando a preceptora Amarela 1 relata que "[...] os residentes ficaram parados, assim, parados na porta. Como se quisessem dizer 'eu não acredito que ele esteja fazendo isso". O relato é posto com orgulho, como se naquele momento o processo de ensino e aprendizagem fosse consolidado através da conduta "modelo" que o preceptor teve, ou seja, através do fato dele ter executado a ação certa. Assim, a preceptora também fortalece seu poder de agir no gênero profissional. Nesse IC o preceptor entrou em atividade, rompeu com os desafios que imobilizariam o seu poder de agir e se fortaleceu nas pactuações coletivas para efetivar seu exercício, agindo em competência.

Segundo Zarifian (2003), a competência é a inteligência prática para situações que se apoiam sobre os conhecimentos adquiridos e os transformam com tanto mais força quanto mais aumenta a complexidade das situações. Essa construção de competências é processual e sofre transfiguração devido ao efeito adaptativo do homem às suas condições de existência, sendo o principal recurso do professor a "postura reflexiva", definida como sua capacidade de observar, regular, inovar e aprender com os outros e com as experiências (AFONSO; SILVEIRA, 2012). Nesse incidente crítico, a postura reflexiva do preceptor foi delineada por meio do agir em competência através da regulação profissional. Todavia, a expansão dessa ação, gerando reflexão dos residentes, não ocorreu no relato.

No IC que se segue é possível observar os fatores psicossociais inerentes ao trabalhador na perspectiva da habilidade social que o preceptor em cena é convocado para utilizar em seu exercício profissional. Utilizaremos a definição de habilidades sociais como conjunto de comportamentos emitidos diante das demandas de uma situação interpessoal, desde que maximizem os ganhos e reduzam as perdas para as interações sociais (SILVA; CARRARA, 2010). 
O residente tava descendo a rampa e perguntou quem tava no plantão da UTI. Quando eu estou no plantão da UTI, embora não seja a minha obrigação, eu fico com os residentes, né? Aí, ela [residente], quando soube que era eu, ela fez uma careta: "Ah, que saco!" [fala da residente]. Ah, ah [gargalhadas da preceptora ao relatar]. [Logo em seguida, a preceptora muda o tom de voz e fala] E aí, eu estava de frente para ela, aí ela disse: "Ah! Você! Eu tenho tanto caso para discutir com você”. Eu disse assim: “Oh! Meu amor, não seja, não, falsa, não, discuta com o plantonista da emergência, ele é mais competente que eu [fala com ironia e muda o tom de voz]". Eu me lembrei disso, embora não seja exatamente isso. Isso é o incidente 01 que eu me lembro. Esse foi o incidente que eu me lembrei. Mas, aí, depois, na outra semana que teve reunião com os residentes e, aí, eu coloquei para eles uma situação que é um desenho de um [...] que chama Dr. Brinquedo, que é um interno, que é um ursinho que faz questão de aprender o ofício de consertar brinquedo. E que ele se chama de residente. E no final. Ah, ah, alegria do bichinho é quando a doutora precisa sair e deixa para ele [...] a função de substituir ela. E ele fica muito feliz, então eu coloquei para eles que estar na residência é uma escolha de cada um, que ninguém foi obrigado, que as regras não foram inventadas, nem por mim, nem pelo hospital, e que são regras que são criadas pelo MEC. E que, para fazer jus ao certificado, cada um precisa de cumprir os requisitos. E, aí, interessante que mexe com todas as pessoas que são envolvidas, menos com as pessoas para quem foi o recado. Ah, ah [gargalhada seguida de seriedade]. (Coral 5).

É possível observar que no trecho "“Ah! Você! Eu tenho caso para discutir com você.' Eu disse assim: 'Oh! Meu amor, não seja, não, falsa, não, discuta com o plantonista da emergência, ele é mais competente que eu"” a reduzida capacidade de interação social caracteriza-se como fator psicossocial que impacta diretamente na relação de ensino e aprendizagem.

Perrenoud (2000) parte da perspectiva de que os seres humanos se desenvolvem pelas relações que estabelecem com o seu meio. Desta forma, cada pessoa desenvolveria competências voltadas para a resolução de problemas de maneira diferente. Diante dessa construção, podemos entender que talvez a habilidade social seja o fator psicossocial inerente ao trabalhador que mais impacta no exercício profissional do preceptor, independendo da atribuição de positividade ou negatividade.

A afirmação anterior sustenta-se nas Diretrizes Curriculares Nacionais de Medicina (2014), que estabelecem, em seu artigo 19, a área de competência da Educação em Saúde pautada em três ações-chave: identificação de necessidades de aprendizagem individual e coletiva; promoção da construção e socialização do conhecimento; promoção do pensamento científico e crítico e apoio à produção de novos conhecimentos. Para serem desenvolvidas, essas ações-chave precisam de comportamentos conscientes pautados na comunicação assertiva, visando a interação social (BRASIL, 2014).

Os ICs apresentados evidenciaram a influência dos fatores psicossociais inerentes ao trabalhador impactando seu exercício profissional. Na ótica da Clínica da Atividade, é possível se aproximar da subjetividade presente no exercício desse preceptor, bem como 
da forma como se dá a construção de sua identidade coletiva. Todavia, torna-se necessário o entendimento de que os fatores psicossociais do trabalho não podem imobilizar o poder de agir do preceptor, uma vez que a imobilização cristaliza a ação e impossibilita a formação desse profissional para reformulação e transformação de suas práticas.

\subsubsection{Categoria II: Fatores psicossociais internos do trabalho}

Os fatores internos do trabalho podem ser entendidos como a reunião das condições do ambiente de trabalho, das tarefas, do grupo de trabalho e da própria organização, bem como de outros aspectos (ZANELLI; KANNAN, 2018). A seguir, são apresentadas situações vivenciadas pelos participantes da pesquisa como sujeitos que tiveram seu cotidiano da docência atravessado por fatores internos do trabalho.

[...] Várias vezes, a gente quis entubar e o laringoscópio quebrou. Uma vez, a residente chorou [...] uma vez, ela [residente] estava fazendo uma laringoscopia, aí, tentando, e o laringoscópio apagava, apagava, apagava. Aí, a gente começou a procurar no centro cirúrgico emprestado, não tinha para emprestar. O pessoal da cirurgia não tinha, o resto [outros laringoscópios] estava na manutenção, aí, agora a menina [residente] começou a chorar. Eu "calma, calma, calma", até que o laringoscópio funcionou. Com aquele pouquinho de luz que tinha, eu entubei. A aluna, ela: "Mas, doutora, eu ia matar a paciente, eu não ia conseguir, porque eu não enxergo". "Calma, a culpa não é sua" [resposta da preceptora]. Porque o sistema faz muita coisa assim, que você tem que se adequar. Você tem que sobreviver ao sistema, né? (Amarela $1)$.

[...] Olha, é muito difícil, olha, a gente mandou, olha, a gente mandou agora, um trabalho, agora, para um congresso de endocrinologia e, aí, o retorno, a gente ficou, os meninos [residentes] ficaram naquela ansiedade e, infelizmente, e não foi [...] aceito. Não foi aceito porque ainda faltavam alguns outros dados, era um caso interessante, um "cricir...", mas não tinha mais subsídio para ir mais além, não fazia a ultrassom de tireoide, aqui só faz ultrassom de urgência. A gente não conseguiu dosar os hormônios: TSH, T4 livre, T3, os outros hormônios que precisava, porque todo trabalho precisa do acervo científico também. A gente tinha o diagnóstico, tinha o exame, mas isso era pouco, mas, mesmo assim, os meninos [residentes] fizeram o trabalho. A gente enviou até como forma de incentivo também, mas, aí, todos ficaram meio assim, né? Porque não foi aceito. Olha, gente, esse é o primeiro de muitos, né? (Mostarda 3).

Os preceptores colocam situações que enfrentam e com as quais, muitas vezes, acreditam saber lidar (superlotação, equipamentos sucateados, ausência de certos exames e medicações e falta de condições básicas de trabalho), mas que impossibilitam a ação da assistência e, consequentemente, da docência.

Ao agir o trabalhador não lida somente com o executado, ou seja, com a atividade do trabalho, mas com todas as possibilidades que necessitam ser deixadas para trás para 
que uma em especial se efetive. Nesse processo de escolha esconde-se um diálogo interno no qual o sujeito define os caminhos de sua ação (CLOT, 2007).

Nesse caso, o movimento psíquico já é um agir do sujeito a ser explorado. É nesse espaço que está presente o que não se faz, o que se tenta fazer sem ser bem sucedido - o drama dos fracassos -, o que se desejaria ou poderia ter feito e o que pensa ser capaz de fazer noutro lugar. A esse espaço Clot denomina real da atividade (PINHEIRO et al., 2016). Ao afirmar "Várias vezes, a gente quis entubar e o laringoscópio quebrou", sem saber, a preceptora (Amarela 1) faz referência à dimensão do trabalho prescrito, colocando em perspectiva o real da atividade, o imprevisível no contato com a realidade, fator que impulsiona a subjetividade. A respeito disso, Bendassolli e Soboll (2010) afirmam que o ato coloca o sujeito em contato direto com o real e com uma parcela de risco inerente a toda atividade: risco de fracasso, risco de erro e risco da criatividade, que abre espaço para o desenvolvimento da subjetividade e para a expansão ou não do poder de agir.

No relato que se segue é possível observar o fator psicossocial interno ao trabalho, na perspectiva da condição da tarefa e do grupo de trabalho. Mesmo diante da interferência desses fatores no exercício da preceptoria, é possível destacar o aparecimento da competência ligada à atenção à saúde.

\begin{abstract}
Eu me estresso muito com o *** [hospital de referência], a gente pega muito HIV [paciente soropositivo] e TB [paciente com tuberculose], a gente pega muita TB. Toda semana tem uma TB no *** [hospital em que é preceptora]. Semana passada, eu me estressei porque chegou um paciente convulsionando com 31 anos. Aí, eu fiz o diagnóstico, era uma meningoencefalite pósarbovirose. Ele [paciente] fez uma virose, quinze dias depois ele rebaixou, convulsionou e, aí, a tomografia normal, era uma meningoencefalite pósarbovirose. Aí, chamei neuro, ele fez líquor. Clássico [fala incisiva]. Aí, liguei para $o^{* * *}$ [hospital de referência]: "Não tem vaga, não" [resposta do hospital de referência]. "Esse paciente precisa de isolamento por 24 horas" [fala com indignação]. "Sim" [resposta do hospital]. "Mas ele tá na vermelha [ala do hospital], diante de 60 outros pacientes [fala com indignação]. Como vou isolar?". "Aí, não é um problema nosso" [resposta do hospital]. "Como não é um problema nosso? Se você que trata de doença infectocontagiosa, não sou eu. Eu já tô com TB, um HIV e agora um meningoencefalite" [resposta da preceptora]. Ah, *** [fala o nome da entrevistadora]! Não tem como você ter juízo o tempo todo, sanidade mental. Tem dias que você descompensa. Não tem como não descompensar. Não tem como incentivar o tempo todo os estudantes. "Ah! Aqui é bom. Não, vai dar tudo certo!" [em tom irônico]. Você dá o diagnóstico, você tem o recurso básico, que é conhecimento, mas todo o resto é falho. (Amarela 1).
\end{abstract}

No trecho “Aí, não é um problema nosso" (resposta do hospital de referência), o comportamento de desresponsabilização, por parte do hospital, e a falha no processo de regulação governamental podem ser caracterizados como fatores psicossociais da 
condição da tarefa interferindo no exercício da preceptora. Todavia, ainda é possível observar nesse IC o aparecimento da competência de atenção à saúde: mesmo diante da interferência dos fatores psicossociais internos ao trabalho no fazer dos preceptores, eles, em sua grande maioria, conseguem agir em competência na perspectiva da atenção à saúde, não imobilizando a sua ação assistencial.

Essa afirmação é evidenciada por Botti e Rego (2011), cujos achados elucidam que, ao longo da história da RM, os médicos com mais experiência e domínio da prática foram considerados os melhores professores. A literatura ressalta que o modelo educacional brasileiro tem a característica de privilegiar, desde a sua implantação, o domínio de conhecimentos e experiências profissionais como pré-requisitos necessários àqueles interessados em atuar como docentes nas universidades e demais instituições de ensino superior do país (RIBEIRO, 2012).

Destaca-se o trecho da fala da preceptora: "Você dá o diagnóstico, você tem o recurso básico, que é conhecimento, mas todo o resto é falho". Ao longo do relato fica claro que a preceptora sabe exatamente o que deve fazer diante da assistência a ser prestada, porém deixa explícita a dificuldade de romper com as limitações estruturais da cena e de estabelecer o processo de ensino-aprendizagem: "Não tem como incentivar o tempo todo os estudantes. 'Ah! Aqui é bom. Não, vai dar tudo certo!' [em tom irônico]”.

A fala da preceptora vai ao encontro do perfil delineado dos preceptores deste estudo ao demonstrar a fragilidade no processo de sua formação, a falta de formação continuada e permanente em saúde na instituição onde são preceptores e a ausência de formação pedagógica.

Apesar de todas as políticas, legislações e programas desenvolvidos pelos ministérios da Saúde e da Educação, ainda estamos distantes de efetivar as DCN quanto à função norteadora de impulsionar a orientação profissional nas instituições formadoras na área da saúde, sendo o treinamento dos estudantes e residentes um desafio (WUILLAUME, 2000). Elucida-se, assim, a importância de que se entenda o exercício da preceptoria reconhecendo o papel do preceptor como mediador do processo de ensinoaprendizagem, sendo premente a discussão de estratégias para a sua formação.

Nessa perspectiva ressaltamos Perrenoud (2000), quando este coloca que é impossível pensar a formação de futuros professores sem um observatório das práticas e das profissões de ensino, cuja missão não seria pensar a formação do professor, mas possibilitar uma imagem realista dos problemas, dos dilemas que enfrentam, das decisões 
que tomam, dos gestos profissionais que realizam e que estão presentes no seu dia a dia. Ressalta-se, dessa forma, a importância de uma formação pautada na realidade.

Urge a necessidade da formação desses preceptores que já estão no exercício da preceptoria da residência médica da emergência. Como bem coloca Clot (2010), a clínica da atividade tem como propósito a transformação do trabalho, por meio da análise do próprio trabalhador. Sendo assim, a formação desses preceptores pode e deve se dar no serviço, no cotidiano do trabalho. Todavia, é necessário criar espaços de discussão das práticas, com olhar específico para a subjetividade desses atores, no intuito da tomada de consciência através da reflexão da atividade e do real da atividade, na perspectiva de reformulação do poder de agir, do surgimento de novas competências e do fortalecimento da identidade profissional através do gênero profissional, dando vazão ao potencial criativo e inovador.

A convergência entre a Clínica da Atividade e a política de Educação Permanente em Saúde (EPS) é necessária e oportuna, uma vez que a EPS se configura como proposta de aprendizagem no trabalho por meio da qual o aprender e o ensinar são incorporados ao cotidiano das organizações (BRASIL, 2018). A EPS se baseia na aprendizagem significativa e na possibilidade de transformar as práticas profissionais.

Os espaços de EPS facilitam a formação pedagógica dos preceptores através da problematização de experiências concretas da emergência, além de possibilitar a autonomia no seu processo de trabalho, partindo da atividade prescrita como um referencial, mas não da necessidade de concretizar a prescrição. Assim, amplia-se o repertório de competências pedagógicas utilizadas, bem como emerge a possibilidade de uma transformação efetiva, na qual ensino, aprendizagem, assistência, gestão e usuário se aproximam, se transformam e influenciam novas atividades.

\section{Considerações finais}

Este estudo qualitativo permitiu analisar a influência dos fatores psicossociais do trabalho através do relato de incidentes críticos do exercício pedagógico de preceptores na Residência Médica de um hospital público de emergência. Na perspectiva dos incidentes críticos, foi possível identificar a complexidade do cenário da emergência ao evidenciarmos os fatores psicossociais do trabalho inerentes ao trabalhador, tais como lócus de controle, habilidades sociais e enfrentamento do estresse. Além disso, também foram reconhecidos os fatores internos ao trabalho, como condições do ambiente de 
trabalho e condições das tarefas, que influenciam de modo a favorecer ou dificultar o exercício pedagógico do preceptor.

Vale destacar que o fenômeno apresentado nos parágrafos anteriores ocorre de forma orquestrada e interligada, num princípio de ação e reação, em que a subjetividade é elemento-chave para o entendimento do exercício pedagógico do preceptor. Ela está ligada à cognição, às emoções, às experiências, às crenças e aos valores, delimitando a forma como se estabelece a atividade do preceptor, mobilizando ou imobilizando o seu poder de agir em competência.

Nos relatos emergiram comportamentos permeados pela competência da atenção à saúde, em detrimento das competências pedagógicas. Isso nos aproxima da história da Residência Médica, através da experiência e do domínio da prática. Essa afirmativa corrobora o delineamento do perfil dos participantes deste estudo quando se constata a ausência de formação pedagógica e de educação permanente em saúde.

A formação médica baseada na prescrição imobiliza, muitas vezes, o agir em competência do preceptor da emergência. É necessário pensar uma formação que coloque o sujeito em contato direto com o real e com uma parcela de risco inerente a toda atividade.

A técnica do incidente crítico utilizada para a coleta dos dados demonstrou ser potente para a avaliação do exercício do preceptor, uma vez que possibilita visualizar três aspectos presentes no trabalho através dos relatos de situações que impactam, de alguma maneira, o cotidiano de suas atividades: a cognição, a afetividade e a resolutividade da situação.

O exercício (bem como a formação) da Medicina é a produção de um ato criativo que, como expressão da subjetividade humana, estabelece uma conexão entre médico e o paciente (ZAIDHAFT, 2019). Nesse sentido, se faz importante o aporte da Clínica da Atividade, possibilitando a análise dos ICs por meio do acesso à subjetividade presente no fazer do preceptor, impulsionando uma relação dialógica do profissional com a sua atividade e lhe possibilitando ser protagonista na análise de seu trabalho.

O estudo evidenciou que, como aporte teórico e metodológico, a Clínica da Atividade favorece o fortalecimento dos espaços de EPS. Assim sendo, possibilita a identificação de estratégias pedagógicas para ativar micropolíticas, subjetivações, protagonismo, implicação e (re)invenção de atores e de coletivos.

Todavia, é imprescindível o deslocamento da macropolítica de educação para as micropolíticas de transformação dessa prática, por meio de: melhoria na infraestrutura do 
serviço de emergência; estruturação de um núcleo docente de preceptores; fortalecimento dos espaços de EPS, através da formação de facilitadores de EPS na Técnica do Incidente Crítico, com o método de "instrução ao sósia"; elaboração de projetos contínuos para capacitação pedagógica dos preceptores, tendo como base a problematização e a aprendizagem transformadora.

A potencialização dos espaços de educação permanente em saúde é fundamental para que a problematização das atividades cotidianas seja pauta permanente de mobilização transformadora e criativa, assim como de reinvenção da própria profissão diante do que está posto na realidade do cenário da emergência. Dessa forma, conclui-se que, a despeito de todos os desafios, somente num cenário educacional em transformação podemos construir uma prática médica também transformadora.

\section{Referências}

AFONSO, D. H.; SILVEIRA, L. M. C. Os desafios na formação de futuros preceptores no contexto de reorientação da educação médica. Revista HUPE, Rio de Janeiro, v. 11, n. 1, p. 8286, dez. 2012.

BAKHTIN, M. Estética da criação verbal. Tradução de Paulo Bezerra. 2. ed. São Paulo: Martins Fontes, 2003.

BARDIN, L. Organização da análise. In: BARDIN, L. Análise de conteúdo. 7. ed. São Paulo: Edições 70, 2011. p. 125-131.

BARROS, M. E. et al. A técnica do incidente crítico: uma estratégia de gestão na saúde materno infantil. Revista Inova Saúde, Criciúma, v. 6, n. 1, p. 140-154, jul. 2017.

BENDASSOLLI, P. F.; SOBOLL, L. A. P. Introdução às clínicas do trabalho: aportes teóricos, pressupostos e aplicações. In: BENDASSOLLI, P. F.; SOBOLL, L. A. P. (org.). Clínicas do trabalho: novas perspectivas para compreensão do trabalho na atualidade. São Paulo: Atlas, 2010. p. 3-21.

BORGES, M. E. S. Trabalho e gestão de si: para além dos "recursos humanos". Cadernos de Psicologia Social do Trabalho, São Paulo, v. 7, p. 41-49, nov. 2004.

BOTTI, S. H. O.; REGO, S. T. A. Docente-clínico: o complexo papel do preceptor na residência médica. Physis: Revista de Saúde Coletiva, Rio de Janeiro, v. 21, n. 1, p. 65-85, 2011.

BRASIL. Decreto $\mathbf{n}^{\mathbf{0}} \mathbf{8 0 . 2 8 1}$, de 05 de setembro de 1977. Regulamenta a Residência Médica, cria a Comissão Nacional de Residência Médica e dá outras providências. Brasília: República Federativa do Brasil, 1977.

BRASIL. Política Nacional de Educação Permanente em Saúde: o que se tem feito para o seu fortalecimento? Brasília: Ministério da Saúde, 2018.

BRASIL. Portaria no 2.048, de 02 de novembro de 2002. Dispõe sobre o Regulamento Técnico dos Sistemas Estaduais de Urgência. Brasília: Ministério da Saúde, 2002. 
BRASIL. Resolução CNRM no 2, de 17 de maio de 2006. Dispõe sobre requisitos mínimos dos Programas de Residência Médica e dá outras providências. Brasília: Ministério da Educação, 2006.

BRASIL. Resolução CNE/CES no 3, de 20 de junho de 2014. Institui Diretrizes Curriculares Nacionais do Curso de Graduação em Medicina e dá outras providências. Brasília: Ministério da Educação, 2014.

CASTELLS, M. A.; CAMPOS, C. E. A.; ROMANO, V. F. Residência em medicina de família e comunidade: atividades da preceptoria. Revista Brasileira de Educação Médica, Brasília, v. 40, n. 3, p. 461-469, jul./set. 2016.

CECILIO, L. C. O. Escolhas para inovarmos na produção do cuidado, das práticas e do conhecimento: como não fazermos "mais do mesmo"? Saúde e sociedade, São Paulo, v. 21, n. 2, p. 280-289, abr./jul. 2012.

CLOT, Y. et al. Entrevista: Yves Clot. Cadernos de Psicologia Social do Trabalho, São Paulo, v. 9, n. 2, p. 99-107, jun. 2006.

CLOT, Y. A função psicológica do trabalho. 2. ed. Petrópolis: Vozes, 2007.

CLOT, Y. Entrevista. Mosaico: Estudos em Psicologia, Belo Horizonte, v. 2, n. 1, p. 65-70, jan./jun. 2008.

CLOT, Y. Trabalho e poder de agir. Belo Horizonte: Fabrefactum, 2010.

CLOT, Y. Clínica do trabalho e clínica da atividade. In: BENDASSOLLI, P. F.; SOBOLL, L. A. P. (org.). Clínicas do trabalho: novas perspectivas para compreensão do trabalho na atualidade. São Paulo: Atlas, 2010. p. 71-83.

DAL PAI, D.; LAUTERT, L. Work under urgency and emergency and its relation with the health of nursing professionals. Rev. Latino-am. Enfermagem, São Paulo, v. 16, n. 3, p. 439444, maio./jun. 2008.

FEUERWERKER, L. C. M. Micropolítica e saúde: produção do cuidado, gestão e formação. Porto Alegre: Rede UNIDA, 2014.

FLANAGAN, J. C. The critical incident technique. Psychological bulletin, v. 51, n. 4, p. 327$358,1954$.

FRENK, J. et al. Health professionals for a new century: transforming education to strengthen health systems in an interdependent world. Lancet, Inglaterra, v. 376, n. 9756, p. 1923-1958, nov. 2010.

GARLET, E. R. et al. Organização do trabalho de uma equipe de saúde no atendimento ao usuário em situações de urgência e emergência. Texto-Contexto Enfermagem, Florianópolis, v. 18, n. 2, p. 266-272, abr./jun. 2009.

GOLDIM, J. R. Aspectos éticos da assistência em situações de emergência e urgência. 2. ed. Porto Alegre: UFRS, 2003.

INTERNATIONAL LABOUR ORGANIZATION. Psychosocial factors at work: recognition and control. Geneva: ILO Publications, 1986. 
LIMA, M. E. Abordagens clínicas e saúde mental no trabalho. In: BENDASSOLLI, P. F.; SOBOLL, L. A. (org.). Clínicas do trabalho: novas perspectivas para compreensão do trabalho na atualidade. São Paulo: Atlas, 2011. p. 227-253.

MALHEIROS, B. T. Metodologia da pesquisa em educação. Rio de Janeiro: LTC, 2011.

MARTINS, G. A. Estudo de caso: uma reflexão sobre a aplicabilidade em pesquisa no Brasil. Revista de Contabilidade e Organizações, São Paulo, v. 2, n. 2, p. 9-18, jan./abr. 2008.

MINAYO, M. C. S. O desafio do conhecimento: pesquisa qualitativa em saúde. 8. ed. São Paulo: Hucitec, 2004.

NAUJORKS, C. J. Cotidiano e Identidade na Clínica da Atividade e na Ergologia. PSI UNISC - Revista do Departamento de Psicologia, Santa Cruz do Sul, v. 2, n. 1, p. 33-47, jan./jun. 2018.

PERRENOUD, P. Novas competências para ensinar. Porto Alegre: Artmed, 2000.

PERRENOUD, P. et al. As competências para ensinar no século XXI: a formação dos professores e o desafio da avaliação. Porto Alegre: Artmed Editora, 2002.

PINHEIRO, F. P. H. A. et al. Clínica da atividade: conceitos e fundamentos teóricos. Arquivos Brasileiros de Psicologia, Rio de Janeiro, v. 68, n. 3, p. 110-124, dez. 2016.

RIBEIRO, E. C. O. Exercício da preceptoria: espaço de desenvolvimento de práticas de educação permanente. Rev do Hosp Univ Pedro Hernesto UERJ, Rio de Janeiro, v. 11, n. 1, p. 77-81, jan./abr. 2012.

ROCHA, C. T. M.; AMADOR, F. S. A respeito do conceito de experiência na clínica da atividade. Pesquisas e práticas psicossociais, São João del Rei, v. 13, n. 2, p. 1-15, maio./ago. 2018.

SANT'ANA, E. R. R. B.; PEREIRA, E. R. S. Preceptoria Médica em Serviço de Emergência e Urgência Hospitalar na Perspectiva de Médicos. Revista Brasileira de Educação Médica, Rio de Janeiro, v. 40, n. 2, p. 204-215, abr./jun. 2016.

SHIKASHO, L. Os Programas de Residência e a integralidade da atenção: um estudo sobre a micropolítica do trabalho e da formação em saúde. 2013. Dissertação (Mestrado em Saúde Coletiva) - Universidade Federal de Juiz de Fora, Juiz de Fora, 2013.

SILVA, A. T. B.; CARRARA, K. Habilidades sociais e análise do comportamento: compatibilidades e dissensões conceitual-metodológicas. Psicologia em Revista, Belo Horizonte, v. 16, n. 2, p. 330-350, ago. 2010.

SILVA, K. L.; MATOS, J. A. V; FRANÇA, B. D. A construção da educação permanente no processo de trabalho em saúde no estado de Minas Gerais, Brasil. Escola Anna Nery, Rio de Janeiro, v. 21, n. 4, p. 1-8, 2017.

SOARES, A. C. P. et al. A importância da regulamentação da preceptoria para a melhoria da qualidade dos programas de residência médica na Amazônia Ocidental. Cadernos ABEM, Rio de Janeiro, v. 9, n.9, p. 14-22, out. 2013.

TELLES, A. L.; ALVAREZ, D. Interfaces ergonomia-ergologia: uma discussão sobre o trabalho prescrito e normas antecedentes. In: FIGUEIREDO, M. et al. (org.). Labirintos do trabalho: interrogações e olhares sobre o trabalho vivo. Rio de Janeiro: DP\&A, 2005. p. 63-69. 
VALENTIM, M. R. S.; SANTOS, M. L. S. C. Políticas de saúde em emergência e a enfermagem. Revista de Enfermagem, Rio de Janeiro, v.62, n. 2, p. 285-289, mar./abr. 2009.

WORLD HEALTH ORGANIZATION. Transforming and scaling up health professional's education and training. Geneva: World Health Organization, 2013.

WUILLAUME, S. M. O processo ensino-aprendizagem na residência médica em pediatria: uma análise. 2000. Tese (Doutorado em Saúde da Criança e da Mulher) - Fundação Oswaldo Cruz, Rio de Janeiro, 2000.

ZAIDHAFT, S. A saúde mental dos estudantes de medicina: reminiscências e conjecturas de um mestre-escola. Revista de Medicina, São Paulo, v. 98, n. 2, p. 86-98, mar./abr. 2019.

ZANELLI, J. C.; KANNAN, L. A. Fatores de risco e de proteção psicossocial: organizações que emancipam ou que matam. Lages: Editora da Uniplac, 2018.

ZARIFIAN, P. O modelo da competência: trajetória histórica, desafios atuais e propostas. São Paulo: Editora Senac, 2003.

Recebido em: 28 de janeiro de 2020.

Aceito em: 02 de março de 2020. 